\title{
Endoscopic Laser Cordotomy Versus Coblator Cordectomy: Our Experience in Managing Bilateral Abductor Paralysis
}

\author{
${ }^{1}$ Ashwani Sethi, ${ }^{2}$ Awadhesh K Mishra, ${ }^{3}$ Deepika Sethi
}

\begin{abstract}
Introduction: Bilateral abductor vocal fold paralysis is a potentially challenging surgical entity. Various surgical options have been proposed for managing this condition. The present study aims to share our experience of using two established surgical modalities in managing this condition.
\end{abstract}

Study design: Retrospective review.

Setting: Tertiary health care center.

Materials and methods: Twenty-three consecutive patients meeting inclusion criteria undergoing posterior cordotomy using $\mathrm{CO}_{2}$ laser $(\mathrm{n}=9)$ and posterior cordectomy using coblator $(\mathrm{n}=$ 14) were included in this study. Preoperative subjective voice analysis was done and compared with measurements at 6 months post procedure. Parameters studied included voice handicap index $(\mathrm{VHI})$, the need for repeat procedures, the effect of decannulation and subjective improvement in respiratory distress.

Results: In all the patients undergoing these surgical procedures, there was a significant improvement in the airway as adjudged by the postoperative subjective improvement in respiratory distress (in five non-tracheostomized patients) and uneventful decannulation (in 18 tracheostomized patients). However, there was no statistically significant difference in either of the two techniques. The postoperative VHI scores showed no statistically significant difference with the preoperative assessment using either of the techniques. Two of the patients in the $\mathrm{CO}_{2}$ laser group and one patient in the coblator group required the procedure to be repeated owing to recurrence of respiratory distress.

Conclusion: Both $\mathrm{CO}_{2}$ laser-assisted posterior cordotomy and coblator assisted posterior cordectomy are safe and efficacious options for the management of compromised airway secondary to bilateral abductor paralysis of vocal folds with comparable outcomes.

\footnotetext{
${ }^{1}$ Associate Professor, ${ }^{2}$ Professor, ${ }^{3}$ Specialist

1,2Department of Otorhinolaryngology-Head Neck Surgery, Army College of Medical Sciences, New Delhi, India

${ }^{3}$ Department of Otorhinolaryngology-Head Neck Surgery, BSA Hospital and Medical College, New Delhi, India

Corresponding Author: Awadhesh K Mishra, Professor, Army College of Medical Sciences, Department of OtorhinolaryngologyHead Neck Surgery, New Delhi, India, e-mail: buddhiprakash@ rediffmail.com
}

Keywords: Bilateral abductor paralysis, Coblator, $\mathrm{CO}_{2}$ laser, Cordectomy, Cordotomy.

How to cite this article: Sethi A, Mishra AK, Sethi D. Endoscopic Laser Cordotomy Versus Coblator Cordectomy: Our Experience in Managing Bilateral Abductor Paralysis. Int $\mathrm{J}$ Phonosurg Laryngol 2018;8(1):26-30.

Source of support: Nil

Conflict of interest: None

\section{INTRODUCTION}

The commonly reported causes for bilateral abductor paralysis of vocal folds secondary to involvement of bilateral recurrent laryngeal nerves include surgical trauma, neurological disorders, extralaryngeal malignancies, non-surgical trauma, etc. ${ }^{1,2}$ It is usually associated with respiratory distress secondary to airway compromise. However, most of these patients have a normal voice. The severity of this dyspnoea is proportional to the amount of glottic chink, body mass of arytenoids, kind of physical activity and presence of any comorbidities. ${ }^{3}$

The various surgical modalities reported for the management of this condition can be broadly divided into endoscopic and external. The endoscopic modalities include medial arytenoidectomy, total arytenoidectomy, posterior cordectomy, ventriculocordectomy, laterofixation and posterior transverse cordotomy. ${ }^{4,5}$ The external procedures include external arytenoidectomy, nervemuscle pedicle anastomosis and laryngeal pacing. ${ }^{6,7}$ The present study aims to share our experience of using an established tool $\left(\mathrm{CO}_{2}\right.$ laser) and a relatively new tool (coblator) in performing a posterior cordotomy / cordectomy for the management of this condition.

\section{MATERIALS AND METHODS}

The study group included 23 patients of either sex with age ranging from 22 to 64 years who presented to the otorhinolaryngology department with complaints of respiratory discomfort secondary to bilateral abductor vocal fold paralysis. Total 18 patients were tracheostomized, and five were not. The patients underwent a thorough otorhinolaryngology examination and general physical examination for any associated systemic illness. Patients 
with vocal cord paralysis were further investigated with the help of chest and neck X-rays, and computed tomography (CT) scans (wherever required) and suitable referrals were sought from chest/medical specialists in order to identify the cause of palsy.

The selected patients also underwent a preoperative voice analysis using a subjective parameter in the form of Hindi version of VHI. The five non-tracheostomized patients were also asked to mark the severity of their dyspnoea on the scale of 1 to 10 with 1 being no dyspnoea even on climbing stairs and 10 being dyspnoea on rest. The 09 initial patients underwent posterior cordotomy using a $\mathrm{CO}_{2}$ laser (acupulse, lumenis) under general anesthesia. The laser settings were kept at $5 \mathrm{~W}$ super pulse mode. The following 14 patients underwent coblator assisted posterior cordectomy. The laryngeal LW wand of the coblator was used for the purpose with the coblator settings of 'eight' for coblation and 'four' for coagulation.

As a routine practice, the cricoarytenoid joints were palpated and passively rotated in all patients on the operating table after general anesthetic induction. This helps



Fig. 1: Coblator-assisted cordectomy initiated at the free margin of true vocal fold just anterior to vocal process.

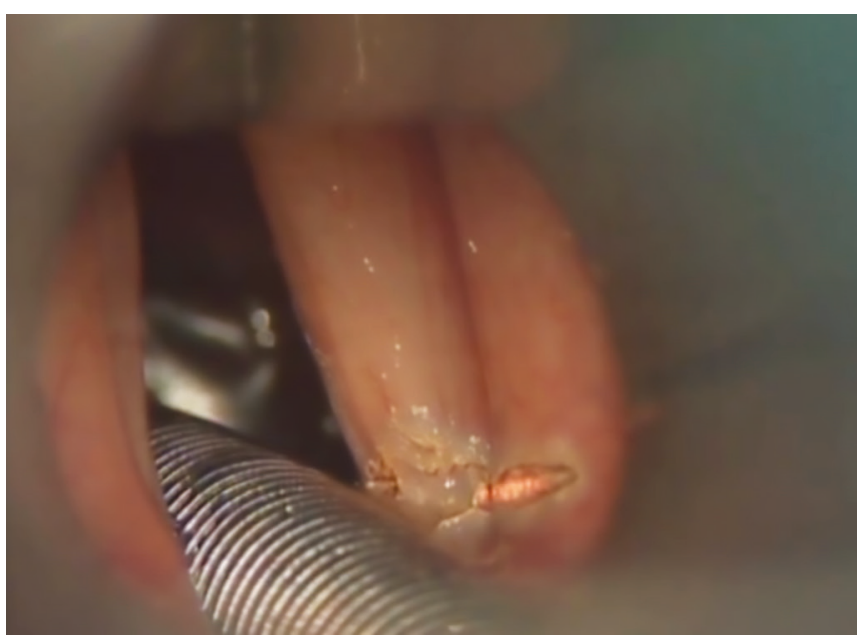

Fig. 3: Incision for laser-assisted cordotomy. in further confirmation of the diagnosis of vocal cord paralysis as the joint can be moved easily on passive rotation, whereas, it is extremely stiff and immobile in case of a joint fixation. In case of posterior glottis stenosis, even the opposite joint moves on rotating one joint. Roughly, $2 \mathrm{~mm}$ by 5 to $6 \mathrm{~mm}$ sleeve of muscle, just anterior to the vocal process was excised in all the cases unilaterally in patients undergoing coblator-assisted posterior cordectomy (Figs 1 and 2). Whereas in patients undergoing $\mathrm{CO}_{2}$ laser-assisted posterior cordotomy, the vocal fold was merely incised just anterior to the vocal process extending 4 to $5 \mathrm{~mm}$ laterally into the false vocal folds (Figs 3 and 4). The procedure was required to be repeated on the opposite side in 3 of the tracheostomized patients (two in the laser group and one in the coblator group) following one week of decannulation owing to a recurrence of dyspnoea. No untoward pre- or post-operative events were recorded. The 18 tracheostomized patients were given a decannulation trial with a subsequent decannulation 48 hours following the surgery. Three patients developed recurrence of dyspnoea one week following

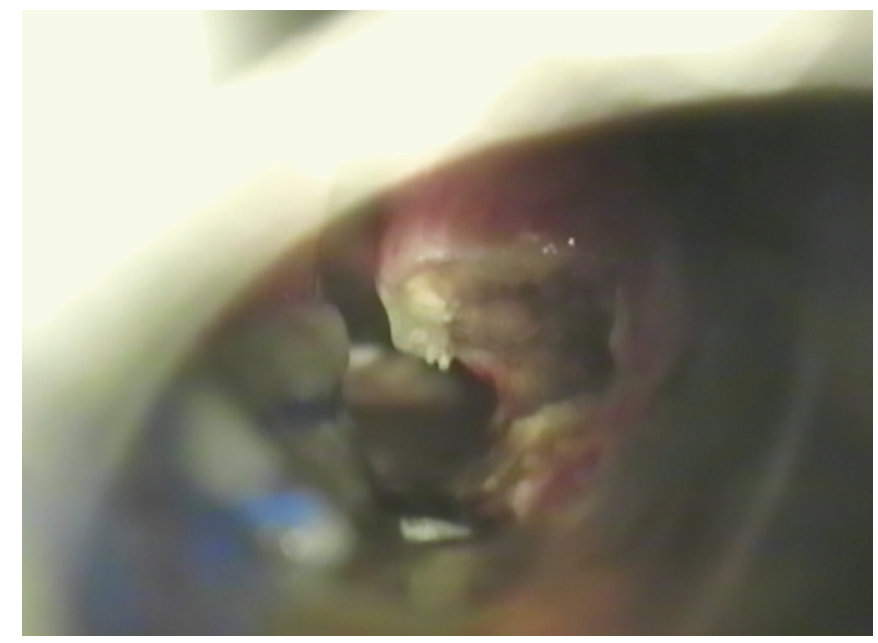

Fig. 2: Coblator-assisted cordectomy completed.

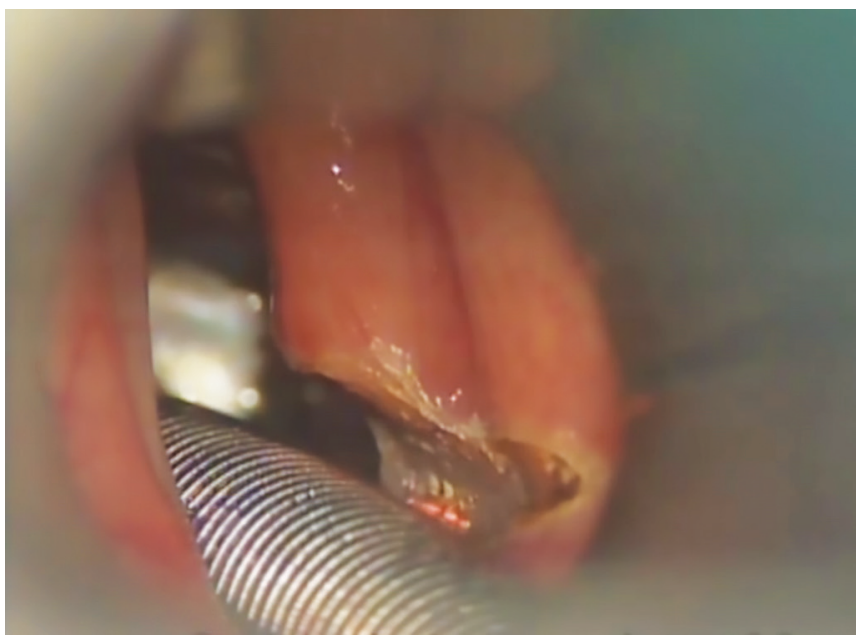

Fig. 4: Laser-assisted cordotomy completed. 
decannulation and underwent a repeat surgical procedure on the opposite cord. All the patients were asked to refill the VHI 3 months following the surgery, and the five non-tracheostomized patients were again asked to mark the severity of their dyspnoea on the scale of 1 to 10. The results were recorded and statistically analyzed (VHI scores only).

\section{VHI Scores}

The average scores of the three domains (i.e., physical, functional and emotional) were analyzed.

\section{RESULTS}

A total of nine patients in the age range of 26-67 years (mean age $=46.9$ ) underwent $\mathrm{CO}_{2}$ laser-assisted posterior cordotomy and a total of 14 patients in the age range of 22 to 64 years (mean age $=48.6$ years) of either sex underwent coblator assisted posterior cordectomy (Fig. 5). Seventeen of these patients developed the palsy secondary to thyroid surgery, four were idiopathic, one was secondary to intubation and one was following a splinter injury to the neck.

\section{VHI Scores}

The mean total VHI scores were $48.9(\mathrm{SD}=19.53)$ preoperatively, and, at 3 months following the surgery, it was $67.8(\mathrm{SD}=26.24)$ for the laser group. The mean total VHI scores were $49.3(\mathrm{SD}=12.73)$ preoperatively, and, at 3 months following the surgery, it was $58.30(\mathrm{SD}=16.51$ ) for the coblator group. There was no significant reduction in total and individual VHI domains postoperatively in both the groups as assessed by paired T-test $(p>0.05)$ (Table 1).

All the 18 tracheostomised patients had a successful decannulation 48 hours following the surgery except for three patients who required a repeat tracheostomy approximately 1 week following decannulation owing to a recurrence of dyspnoea. These patients also underwent a repeat procedure on the opposite cord following which a successful decannulation was done subsequently. The five non-tracheostomised patients had a marked subjective improvement in the severity of dyspnoea. All the 23 patients remained asymptomatic till their last follow up ( minimum follow-up period $=6$ months).

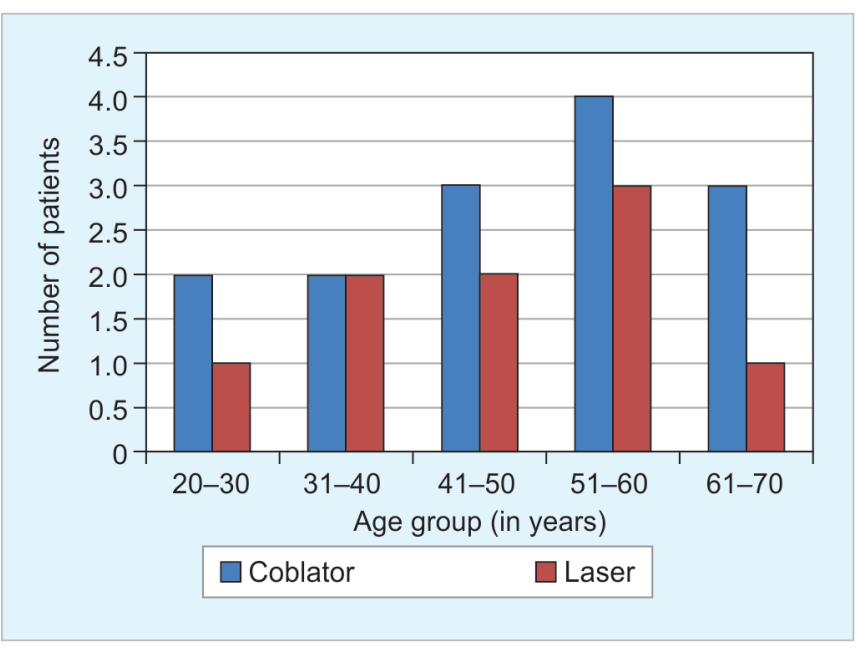

Fig. 5: Age distribution of patients

\section{DISCUSSION}

Patients with bilateral abductor paralysis usually present with dyspnoea. At times, it may present as an emergency with respiratory compromise requiring a tracheostomy. Eighteen of our patients also had to undergo tracheostomy for this reason. However, most of these patients have a relatively well-preserved voice, and dysphonia is not a presenting complaint. ${ }^{2}$ Similarly, none of our patients had complaints of dysphonia.

In our patients, the most common cause for this occurrence was the injury to bilateral recurrent laryngeal nerves following thyroid surgery. This is the most commonly reported cause in literature also. ${ }^{1,2}$ Tracheostomy managed most of the patients racheostomy only for a very long time until the introduction of laser-assisted posterior cordotomy by Dennis and Kashima in $1989 .{ }^{8}$ This procedure involves incising the true vocal fold at the junction of it's anterior two third and posterior third thereby releasing the tension of the glottis sphincter rather than actual removal of the glottal tissue. Nine of our initial patients were managed using this technique. The latter 14 patients were managed with a procedure involving removal of a part of thyroarytenoid muscle from the anterolateral aspect after giving the cordotomy incision. We believe that it further expands the glottic airway. A similar technique was also advocated by Reker and Rudert in $1998 .{ }^{9}$ We utilized a coblator for performing this surgery instead of using a $\mathrm{CO}_{2}$ laser. Although, there are reports of coblator being used for supraglottoplasty in patients with laryngomalacia and epiglottoplasty in

Table 1: Pre- and post-operative VHI scores

\begin{tabular}{|c|c|c|c|c|c|c|c|c|}
\hline & \multicolumn{8}{|c|}{ MEAN VHI } \\
\hline & \multicolumn{2}{|c|}{ Functional domain } & \multicolumn{2}{|c|}{ Physical domain } & \multicolumn{2}{|c|}{ Emotional domain } & \multicolumn{2}{|c|}{ Total } \\
\hline & Laser & Coblator & Laser & Coblator & Laser & Coblator & Laser & Coblator \\
\hline Preoperative value & 17.67 & 17.14 & 17.11 & 17.86 & 14.11 & 14.57 & 48.89 & 49.14 \\
\hline Postoperative value & 23.22 & 23.85 & 24.33 & 24.28 & 20.22 & 19.93 & 67.78 & 58.30 \\
\hline
\end{tabular}


patients with obstructive sleep apnoea syndrome, the use of coblator in the management of bilateral abductor paralysis is scarcely reported. ${ }^{10-13}$ The reported advantage of coblator over $\mathrm{CO}_{2}$ laser is a minimal surrounding tissue charring and damage owing to a lesser rise in temperature in the adjacent tissues. ${ }^{13,14}$ This property of coblator is also responsible for a lesser postoperative edema and an early decannulation. This may be the cause for a lesser incidence of recurrence of respiratory distress due to postoperative edema requiring resurgery in our patients treated with coblator compared to those treated with laser. However, the statistical significance of this could not be ascertained in our study owing to a small sample size. In our experience, one of the clear-cut advantages of using a coblator was the excellent hemostasis that can be achieved preoperatively as compared to the $\mathrm{CO}_{2}$ laser as the same coblator wand could be used for simultaneous coagulation of small blood vessels that may bleed during surgery.

Various other surgical options using lasers have been reported for the management of this condition. These include; cordotomy, cordectomy, partial and complete arytenoidectomy, ventriculocordectomy. ${ }^{4,5}$ Many times, the surgical procedures are also combined in order to achieve a larger and longer-lasting airway expansion. The most commonly combined surgical procedures include a posterior cordectomy with arytenoidectomy. ${ }^{4,15-17}$

The treatment outcomes measured in our study included a validated Hindi version of VHI for voice assessment, and, the outcome of decannulation and subjective improvement in dyspnea for airway assessment. ${ }^{18,19}$ Similarly, these parameters have been used in similar studies in the past as outcome measures. ${ }^{4,16,20}$ The other objective parameter used for assessing airway in the past is spirometry. ${ }^{9,15,17,21}$ We did not find any significant voice deterioration following surgery in any of our patients using either laser or coblator. Laryngeal compensation following cordectomy has been well documented in the past. ${ }^{22}$ There was no statistically significant difference in terms of voice deterioration on comparing both the modalities in spite of attaining a comparatively larger visible glottic space following coblation cordectomy as compared to laser cordotomy. This may be attributed to significantly lesser damage, and subsequent fibrosis, caused by coblation as compared to using a laser.

Various complications associated with the procedure of cordectomy that have been reported in the past include hemorrhage, granuloma formation, immediate worsening of dyspnea and anterior cervical abscess. ${ }^{20,23-25}$ However, we did not encounter any such complication in any of our patients. Although, three of our patients required a repeat tracheostomy following cordectomy on the opposite cord.

\section{CONCLUSION}

Various surgical options are available for the management of bilateral vocal fold abductor paralysis with their respective advantages and disadvantages. $\mathrm{CO}_{2}$ laserassisted posterior cordotomy is a well-established treatment modality for this condition. Application of coblator assisted posterior cordectomy in the management of these patients is a relatively new modality with comparable results as compared to $\mathrm{CO}_{2}$ laser.

\section{REFERENCES}

1. Benninger MS, Gillen JB, Altman JS . Changing etiology of vocal fold immobility. Laryngoscope 1998;108:1346-1350.

2. Holinger LD, Holinger PC, Holinger PH. Etiology of bilateral abductor vocal cord paralysis: a review of 389 cases. Ann Otol Rhinol Laryngol. 1976 Jul-Aug;85(4 Pt 1):428-436.

3. Kleinsasser O, Nolte E . Endolaryngeale Arytaenoidektomie und submuköse partielle Chordektomie bei bilateralen Stimmlippenlähmungen. Laryngorhinootologie 1981; 60:397401.

4. Lisowska G, Sowa $\mathrm{P}(1)$, Misiolek H, Scierski W, Misiolek M. Possibilities of surgical correction of vocal cord palsy after thyroid gland operations. Endokrynol Pol 2015;66(5):412-416.

5. Bajaj Y, Sethi N, Shayah A, Harris AT, Henshaw P, Coatesworth AP, Nicolaides AR. Vocal fold paralysis: role of bilateral transverse cordotomy. J Laryngol Otol 2009 Dec;123(12):1348-1351.

6. Sanders I. Electrical stimulation of laryngeal muscle. Otolaryngol Clin North Am 1991;24(5):1253-1274.

7. Netterville J, Ossoff R. Evaluation and treatment of complications of thyroid and parathyroid surgery. Otolaryngol Clin North Am 1990;23(3):529-552.

8. Dennis DP, Kashima H. Carbon dioxide laser posterior cordotomy for treatment of bilateral vocal cord paralysis. Ann Otol Rhinol Laryngol 1989,98:930-934.

9. Reker U, Rudert H. Modified posterior Dennis and Kashima cordectomy in treatment of bilateral recurrent nerve paralysis. Laryngorhinootologie 1998 Apr;77(4):213-218.

10. Ramprasad VH, Ryan MA, Farjat AE, Eapen RJ, Raynor EM. Practice patterns in supraglottoplasty and perioperative care. Int J Pediatr Otorhinolaryngol 2016 Jul;86:118-123.

11. Cassano M. Endoscopic coblator-assisted epiglottoplasty in "obstructive sleep apnoea syndrome" patients. Clinical Otolaryngology 2016;42(5):1112-1114.

12. Googe B, Nida A, Schweinfurth J. Coblator Arytenoidectomy in the Treatment of Bilateral Vocal Cord Paralysis. Case Reports in Otolaryngology 2015;1-3.

13. Zhang QF, Zhang JJ, Zhang Y, She CP, Ma L. Endoscopic coblation assisted arytenoidectomy in the treatment of bilateral vocal cord paralysis. Zhonghua er bi yan hou tou jing wai ke za zhi= Chinese journal of otorhinolaryngology head and neck surgery. 2013 Jul;48(7):589-591.

14. Magdy EA, Elwany S, El-Daly AS, Abdel-Hadi M, Morshedy MA. Coblation tonsillectomy: a prospective, double-blind, randomised, clinical and histopathological comparison with dissection-ligation, monopolar electrocautery and laser tonsillectomies. J Laryngol Otol 2008;122(3):282290.

15. Misiolek M, Ziora D, Namyslowski G, Misiolek H, Kucia J, Scierski $\mathrm{W}$, et al. Long-term results in patients after combined 
laser total arytenoidectomy with posterior cordectomy for bilateral vocal cord paralysis. Eur Arch Otorhinolaryngol 2007 Aug;264(8):895-900.

16. Misiołek M, Kł bukowski L, Lisowska G, Czecior E, Cierski W, Orecka B, Namysłowski G. Usefulness of laser arytenoidectomy and laterofixation in treatment of bilateral vocal cord paralysis. Otolaryngol Pol 2012 Mar-Apr;66(2): 109-116.

17. Sharan CJ, Bahadur S, Handa KK, Thakar A, Pande JN. Changes in ventilatory function following surgery for bilateral abductor paralysis. Indian J Otolaryngol Head Neck Surg 2009 Sep;61(3):208-212.

18. Datta R, Sethi A, Singh S, Nilakantan A. Venkatesh MD. Translation and Validation of the Voice Handicap Index in Hindi. J Laryngol Voice 2011;1(1):12-17.

19. Sethi A, Datta R, Mishra AK, Singh SP, Sangwan P. Clinical application of the validated Hindi VHI in assessing subjective improvement following microlaryngeal surgeries for benign vocal fold lesions: a preliminary report. J Laryngol Voice 2012;2:89-92
20. Landa M, Luqui I, Gómez J, Martínez Z. Posterior cordectomy. Our experience. Acta Otorrinolaringol Esp 2012 JanFeb;63(1):26-30.

21. Misiolek M(1), Namyslowski G, Warmuzinski K, Karpe J, Rauer R, Misiolek H. The influence of laser arytenoidectomy on ventilation parameters in patients with bilateral vocal cord paralysis. Eur Arch Otorhinolaryngol 2003 Aug;260(7):381-385.

22. Soliman Z, Hosny SM, El-Anwar MW, Quriba AS. Laryngeal Compensation for Voice Production After CO2 Laser Cordectomy. Clin Exp Otorhinolaryngol 2015 Dec;8(4): 402-408.

23. Wang L, Sun S, Wang S, Liang D, Ji W. Clinical observation of traumatic granuloma after CO laser cordectomy and laryngopharyngeal reflux. Zhonghua er bi yan hou tou jing wai ke za zhi= Chinese journal of otorhinolaryngology head and neck surgery. 2014 May;49(5):374-378.

24. Weingarten TN, Bojani K, Scavonetto F, Sprung J. Management of delayed hemorrhage after partial vocal cord cordectomy. J Clin Anesth 2013 Dec;25(8):666-668.

25. Pelaz AC, Rodrigo JP, Mancebo G, Suárez C. Anterior cervical abscess as a complication of $\mathrm{CO} 2$ laser surgery of the larynx. J Craniofac Sur. 2010 May;21(3):790-791. 